\title{
LA SUPERSTICIÓN EN HUME A PARTIR DE UNA LECTURA HEGELIANA: UN ANÁLISIS RESTRICTIVO
}

\author{
Superstition in Hume from a Hegelian reading: a restrictive analysis \\ Margarita Cabrera Cabrera \\ Universidad de Chile, Santiago, Chile \\ margarita.cabrera@ug.uchile.cl
}

\begin{abstract}
Resumen
El artículo que se presenta a continuación tiene como objetivo principal demostrar el carácter restrictivo e insuficiente que tiene Hume respecto del estudio del fenómeno religioso, específicamente, la fe entendida como mera superstición. Lo anterior se debe a que la postura humeana se caracteriza por reducir el conocimiento en general a la experiencia sensoperceptual, por lo tanto, la religión no bastaría para constituirse como un saber en sentido estricto. Para demostrar la insuficiencia del análisis humeano se contrastará con la disposición que presenta la figura del "ilustrado" en la Fenomenología del espíritu de Hegel, pues, en el carácter que presenta la Ilustración, subyace parcialmente la perspectiva que posee Hume respecto de la comprensión de la fe. En consecuencia, se extraerá que no es posible comprender la experiencia religiosa desde una postura ilustrada - o científica - en la medida que su método de estudio solo reconoce elementos rastreables empíricamente.
\end{abstract}

Palabras clave: fe, ilustración, superstición, reino del error.

\begin{abstract}
The main objective of the article presented below is to demonstrate the restrictive and insufficient nature Hume has regarding the study of the religious phenomenon, specifically, faith understood as a mere superstition. Since Hume's position is characterized by reducing general knowledge to the sense perceptual experience, therefore, religion would not be enough to establish itself as a knowledge in the strict sense. In order to demonstrate the inadequacy of the Humean analysis, it will be contrasted with the disposition presented by the figure of the illustrated in the Phenomenology of the Spirit (G.W. Hegel), since the character presented by the Enlightenment partially underlies Hume's perspective regarding the understanding of faith. Consequently, it will be extracted that it is not possible to understand the religious experience from an enlightened or scientific position, because its method of study recognizes only empirically traceable elements.
\end{abstract}

Keywords: faith, superstition, enlightenment, realm of errors.

Fecha de Recepción: 28/07/2019 - Fecha de Aceptación: 23/12/2019 


\section{Introducción}

En sus obras dedicadas a la religión ${ }^{1}$ Hume realiza frecuentemente comentarios irónicos respecto de esta, junto con considerar a la fe como una práctica incomprensible ${ }^{2}$, dado que los objetos de adoración de los feligreses son elementos tales como el pan y el vino en la eucaristía, o las reliquias religiosas. En cambio, en la lectura hegeliana de la fe existen otros componentes que no se vinculan necesariamente a entidades materiales, sino que toma en cuenta prácticas que constituyen a los participantes del rito en una comunidad - lo que permite entender a la fe bajo un horizonte más amplio.

Bajo este contexto, el presente escrito propone constituirse como un análisis restrictivo ${ }^{3}$ de la perspectiva humeana de la fe a través de la lectura de los primeros párrafos ${ }^{4}$ del apartado "Ilustración" de la Fenomenología del Espíritu de Hegel (en adelante $P d G)$. En un primer momento, se contextualizará el cómo se origina la disposición que posee la ilustración respecto de la fe (lo que conlleva como consecuencia una mala comprensión de esta). En un segundo momento, se esclarecerá en qué consiste el 'reino del error' y el modo de concebir la fe -y la relación entre autoconsciencia y fe- en Hegel. Finalmente, en un tercer momento, se expondrán algunos aspectos de la filosofía de la religión de Hume con el fin de comprobar $^{5}$ la existencia de una correspondencia parcial entre la caracterización del ilustrado en $P d G$ y el análisis humeano de la fe. Esto último, apunta a configurarse como un examen de las limitaciones del estudio de la fe en los escritos del filósofo escocés, pues, un conocimiento - en sentido amplio- se concibe más allá de un saber anclado en estudios empíricos.

\footnotetext{
${ }^{1}$ El análisis que se lleva a cabo considera particularmente las prácticas de la religión católica, y no otras religiones como el budismo o hinduismo, por nombrar algunas.

2 Desde la postura humeana al no ser comprensible, entonces, no es racional.

${ }^{3}$ Dado que el objetivo es analizar las limitaciones que tiene Hume respecto de la fe entendida como superstición, este artículo no busca determinar si Hegel o Hume son más o menos ilustrados comparativamente. Así, el examen expuesto a lo largo del escrito no se constituye como un mero contraste entre autores, sino que se configura como una investigación que tiene como foco entender las limitaciones del estudio humeano del fenómeno religioso.

${ }^{4}$ Desde el párrafo 538 hasta el 551, se cita la paginación de las Gesammelte Werke. Meiner, Hamburg 1968 ss., IX: Phänomenologie des Geistes. Edit. por W. Bonsiepen y R. Heede, (consignada al margen derecho).

${ }^{5}$ El examen que se ha llevado a cabo no busca constituirse como una investigación detallada de la obra hegeliana en su totalidad. Además, es importante expresar que no se pretende defender la tesis de que Hegel tuviera en mente la obra humeana para el proyecto que se desarrolló en el apartado "Ilustración", de manera tal que, el ejercicio realizado se formula como una forma de interpretar la filosofía de la religión de Hume para determinar los márgenes de su lectura. Por último, este artículo no se constituye como una comparación histórica, sino de métodos y alcances en la disciplina filosófica.
} 


\section{El origen de la fe e intelección pura}

El apartado de $P d G$ "La cultura y su reino de la realidad" termina con el siguiente llamado: "Esta pura intelección es, por tanto, el espíritu que grita a todas las consciencias: sed para vosotras mismas lo que todas sois en vosotras mismas: racionales" (542). Tal invitación expone el objetivo de la intelección de devenir racional a través de un objeto que se concibe externo e irracional, a saber, la fe. En este mismo sentido, el apartado "Ilustración" 6 comienza de la siguiente manera: "la lucha de la Ilustración contra la superstición, es decir, con la fe vista precisamente desde su perspectiva contraria. En esta lucha se muestra que la Ilustración no se puede diferenciar de su adversario" (Siep 196; énfasis propio).

En $P d G$ Hegel afirma, específicamente al comienzo de la sección "Ilustración" (538), que la pura intelección puede obtener claridad respecto de sí misma en la medida en que se contrapone a lo que claramente ella no es, a saber, la fe. La ilustración, o intelección pura, intenta entender la falsedad de la fe y, a través de esa búsqueda, se relaciona con el mundo; en consecuencia, la fe y la intelección comparten una arista: el distanciamiento del mundo ${ }^{7}$ (pues, la fe se refugia en un mundo trasmundano y la intelección, por su lado, se ocupa de la fe). De todas formas, fe e intelección son diferentes en la medida en que una es la negación de la otra.

La intelección pura no posee contenidos, por ende, para obtenerlos se enfrenta al mundo y a la fe. Dado lo anterior, se observan dos vías posibles: por un lado, se establece el vínculo que existe con el mundo de la cultura, cuya estructura es algo ajeno a la consciencia, y, por otro lado, se constata que dicho mundo no es bueno, puesto que en la cultura se revela que cada individuo se entrega a una estructura normativa que constituye a cada sujeto, lo cual implica que hay un sacrificio personal con el fin de vivir acorde a reglas que se consideran buenas (pero, posteriormente, se devela que esto no es así, porque existe una asimetría entre lo que se considera bueno y lo que realmente ocurre en el mundo). Lo anterior, Hegel lo expone en $P d G$ con referencias explícitas a obras como, por ejemplo, El sobrino de Rameau ${ }^{8}$.

\footnotetext{
${ }^{6}$ Es importante aclarar que la denominación ilustración descrita por Hegel se refiere a una forma de comprensión relativa a un objeto de estudio del ilustrado, en este caso, la fe.

${ }^{7}$ Hegel lo formula de la siguiente manera: "El objeto peculiar contra el que la pura intelección dirige la fuerza del concepto es la fe, como la forma de conciencia pura, contrapuesta a aquélla en el mismo elemento. Pero la pura intelección guarda también relación con el mundo real, pues es, como la fe, el retorno de ella a la pura conciencia" (PdG 538).

${ }^{8}$ En la obra mencionada se da cuenta que las normas son vanas, porque el mundo no logra adecuarse a ellas. En $P d G$ existen referencias explícitas a obras de las bellas letras francesas, tal es el
} 
Desde el punto de vista del ilustrado, la fe permanece idéntica a sí misma, porque su objeto está fuera del mundo de la cultura, por lo mismo, no se relaciona con algo que sea distinto de ella. Dicho de otro modo, como el objeto de la fe no se halla en el mundo terrenal, entonces, la fe no tiene consciencia de sí misma, pues, su objeto no le permite tener claridad respecto de sí misma.

La fe y la intelección observan el 'torbellino' ${ }^{9}$ del mundo, pero la primera se refugia en otro mundo, en cambio, en la intelección obtiene contenidos en la medida que entiende la falsedad de la fe y por esa vía se relaciona con el mundo, lo cual indica que tiene algo en común con ella: el distanciamiento del mundo.

Por su parte, la intelección pura posee dos momentos: primero, se relaciona negativamente con el mundo lo que le produce el sentimiento de náusea, dada la imposibilidad de explicar el mundo (ya que, no es bueno); el segundo momento es el lenguaje $\mathrm{e}^{10}$, el que se establece como el medio por el cual se manifiesta la fractura que tiene la intelección con el mundo. Por consiguiente, la intelección, producto de la fractura, no logra comprender el mundo y queda incapacitada de acción ${ }^{11}$.

La intelección se detiene ante la fe entendida como superstición, dándole un nuevo sentido, a saber, la posibilidad de terminar con su inactividad. Sin embargo, la disposición que posee la ilustración ${ }^{12}$ no le permite comprender a la fe de modo completo, sino sesgadamente ${ }^{13}$. Ahora bien, la intelección pura tiene como objetivo conocerse a sí misma al tener como objeto a la fe; pero, como solo capta una parte de ella, tampoco se comprende a sí misma.

caso de El sobrino de Rameau, ya que en su configuración dialógica posee dos personajes: moi y je, es decir, son dos sujetos que constituyen una unidad. En la obra mencionada, se encuentra el filósofo moral, es decir aquel que exalta la virtud, y, en oposición, además el sobrino de Rameau, el cual es un hedonista que en última instancia evidencia que las normas virtuosas no poseen ningún valor. Ludwig Siep recomienda en la nota 76 de El camino de la fenomenología del espíritu para una comparación detallada entre la obra de Diderot y PdG: «Hegel's Intertextual Dialectic, Diderot's "Le Neveu de Rameau" in: "The Phenomenology of spirit"», in: The Phenomenology of Spirit Reader: Critical and Interpretive Essays, hg. V. Jon Bartley Stewart, Albany 1998, 282-306.

9 Al comienzo de PdG 539 aparece la referencia al torbellino, tal metáfora indica la constante variación del mundo, pues, este nunca se adapta a aquello que se considera bueno.

${ }^{10} \mathrm{El}$ lenguaje es el 'medio simple' por el cual la consciencia tranquila evidencia su fractura, lo que tiene como consecuencia que la intelección pura se torne incapaz de acción alguna. El lenguaje alberga la posibilidad de corromperse y sostener afirmaciones que no se sabe de dónde provienen, a saber, convertirse en habladuría. La referencia se encuentra en PdG 540.

${ }^{11}$ Como se puede observar en la crítica social de la literatura francesa ( $c f$. El sobrino de Rameau o Cándido de Voltaire).

${ }^{12}$ En el apartado "Ilustración” la pura intelección e ilustración, son sinónimos.

${ }^{13}$ Porque la entiende de modo cósico. 


\section{La constitución del 'reino del error'14}

Según el ilustrado, el 'reino del error' se conforma de tres momentos: el vulgo engañado, el clero engañador y, por último, el momento unificador del despotismo que se constituye como una síntesis carente de concepto. El sacerdocio es quien interpreta la verdad, es falso y mal intencionado, puesto que su mensaje se basa en mera representación y credulidad. En cambio, las masas engañadas albergan la posibilidad de autoconsciencia, pero se configuran como 'mala intelección' debido a que esta es precaria o poco desarrollada. Por otro lado, la figura del déspota se explica de la siguiente manera: "El lado de la singularidad que se aísla de la conciencia universal y espontánea es lo contrapuesto a la Ilustración y que ésta no puede tocar de modo inmediato" (PdG 544). Así, el déspota se configura como un elemento que es inasible para la pura intelección.

Existe una arista común entre el ilustrado y el vulgo engañado: la racionalidad; por lo tanto, cabe la posibilidad de comunicación entre ellas. De este modo, la pura intelección aspira a que la masa se libere de lo que no comprende cognitivamente, además busca que los afectos del vulgo no sean manipulados ${ }^{15}$ por la 'mala intelección' ${ }^{16}$. La masa o el vulgo engañado es una unidad singular que no sabe de sí misma, pero existe la posibilidad que pueda adquirir autoconsciencia y pueda devenir libre. La intelección no puede apelar a los sacerdotes, porque son malintencionados, en cambio, el vulgo tiene el germen de la racionalidad, puesto que tienen normatividad ${ }^{17}$ en la sustancia ${ }^{18}$. En la descripción anterior, es posible observar que la pura intelección concibe a las masas como ingenuas ${ }^{19}$, pero también como racionales.

\section{Fe, confianza y autoconsciencia}

La perspectiva que tiene el ilustrado respecto de los sacerdotes es irracionalidad y mentira, en cambio, en el caso del déspota los comprende como 'mala intención'. De manera que la intelección es una perspectiva que tiene como objeto a la fe, la cual comprende sesgadamente, $y$, además, la interpela (ya que sostiene que la fe deposita su creencia en un objeto físico). Sin embargo, los creyentes saben que los

\footnotetext{
${ }^{14}$ La exposición del reino del error comienza en PdG 543.

${ }^{15}$ Dada su mala comprensión.

${ }^{16}$ Los sacerdotes.

${ }^{17}$ La que está prefigurada en los vínculos familiares.

${ }^{18}$ La sustancia es una red de normas con la que la autoconsciencia busca identificarse.

${ }^{19} \mathrm{El}$ pensamiento de las masas es limitado, porque su reflexión no es elaborada; por lo tanto, lo que les está posibilitado concebir son relaciones filiales en la imaginación (por ejemplo, la figura de un Dios padre).
} 
objetos son entes materiales, pero la confianza va más allá de los objetos que se utilizan en el rito como el pan o el vino, sino que existen otros componentes en la liturgia: por ejemplo, la confianza en la comunidad en la que se lleva a cabo las ceremonias religiosas.

La confianza de los participantes del rito hace que cada consciencia particular se transforme en autoconsciencia, pues se obtiene conocimiento de sí mismo y de los otros participantes de la liturgia - los cuales reconocen sus propios límites ${ }^{20}$ y se entregan a las reglas que existen en su comunidad. En otras palabras, la confianza se manifiesta cuando hay certeza de sí y de sí para otros, es decir, se reconoce la libertad en cada individuo. En palabras del filósofo alemán: “La certeza de sí mismo de aquel en quien confío es para mí la certeza de mí mismo; conozco mi ser para mí en él, conozco que él lo reconoce y que es para él fin y esencia" (PdG 550).

Sin embargo, desde la perspectiva del ilustrado se le enrostra a la fe que se equivoca respecto de su objeto: no es posible que Dios sea un objeto material (como el pan en la eucaristía). Pero, la fe no ha olvidado que el pan y el vino son entidades materiales, puesto que no tiene una relación cósica con su objeto. Empero, la fe es un vínculo con el mundo desde una cierta confianza entre los miembros de la comunidad. Para esclarecer este punto es conveniente recoger las palabras de Hegel:

Pero la esencia absoluta ${ }^{21}$ de la fe no es esencialmente la esencia abstracta que se halle más allá de la consciencia creyente, sino que es el espíritu de la comunidad, la unidad de la esencia abstracta y de la autoconsciencia. El que aquella esencia absoluta sea este espíritu de la comunidad implica como momento esencial el obrar de su comunidad; es el espíritu de la comunidad sólo mediante la producción de la consciencia; o, mejor dicho, no sin ser producido por la consciencia; pues por esencial que sea el producir, no es, esencialmente, el fundamento único de la esencia, sino sólo un momento. La esencia es al mismo tiempo en y para sí misma (PdG 550; énfasis propio).

En PdG se ha dejado de manifiesto que la intelección acusa a la fe indicándole que su objeto es fruto de su consciencia. El ilustrado, no obstante, tiende a un comportamiento similar dado que su objeto ${ }^{22}$ es parte de la pura consciencia y no lo reconoce como tal, sino que solo lo concibe como 'mentira' y 'error' (la fe cree en meros objetos físicos). Lo anterior deja de manifiesto que la intelección no toma en cuenta el elemento comunitario de la fe, pues, se convierte en autoconsciencia cuando existe un reconocimiento de cada sujeto como parte de la comunidad; dicho en términos de hegelianos: cada consciencia se convierte en un para-sí.

\footnotetext{
${ }^{20}$ Entre cada sujeto.

${ }^{21}$ Dios.

${ }^{22} \mathrm{La}$ fe.
} 


\section{Credulidad y creencia en Hume}

En $T H N^{23}$ se establece qué es la creencia: una tendencia de la naturaleza humana, la cual, si no se tiene precaución, puede devenir en credulidad o superstición, como la fe. Para caracterizar la creencia es conveniente recoger las palabras de Hume: "Si la consideración de la naturaleza de esta relación, y de la facilidad de transición que le es esencial, puede convencernos, bien; sin embargo, tengo que confesar que para probar un principio tan importante es en la experiencia donde pongo mi mayor confianza $a^{24 "}$ (THN SB 99; énfasis propio). Dado lo anterior, se puede concluir que el autor sostiene que creer es una conducta que propicia el desarrollo de la humanidad, pero su dominio debe supeditarse al dominio causal cuyas reglas ${ }^{25}$ no deben abandonar la experiencia.

Cabe destacar que la creencia no es lo mismo que la creencia religiosa ${ }^{26}$ : la primera es una tendencia natural que no se puede erradicar, la segunda es secundaria y adquirida por testimonios. Dicho de otro modo, la creencia es una inclinación natural que poseen los seres humanos para desenvolverse en el mundo, pero se deben someter a un examen aquellas nociones en las que se cree, es decir, evitar que la creencia se torne credulidad. Hume exhorta al lector a convertirse en un 'hombre sabio', pues estos logran circunscribir la creencia a la demostración empírica:

Un hombre sabio ${ }^{27}$, por consiguiente, ajusta proporcionalmente su creencia a la evidencia. En aquellas conclusiones que se basan en una experiencia infalible, espera el evento con el grado máximo de seguridad, y considera su experiencia pasada como una prueba completa de la futura existencia de ese evento. En otros casos, procede con mayor cautela. Sopesa los experimentos contrarios. Considera qué parte se apoya en un número mayor de experimentos, y hacia ella se inclina con duda y vacilación; y cuando al final fija su juicio, la evidencia no excede lo que propiamente llamamos probabilidad ${ }^{28}$ (EHU 11011; énfasis propio)

${ }^{23}$ La obra humeana se cita según la paginación Selby-Bigge revisada y editada por P.H Nidditch.

${ }^{24}$ En la introducción de THN Hume declara explícitamente que la ciencia de la naturaleza humana debe ampararse en la experiencia.

${ }^{25}$ THN Libro I, Parte III, sección XV.

${ }^{26}$ Hume lo distingue de la siguiente manera: “Parecería, pues, que este concepto previo surge no de un instinto general o de una impresión primaria de la naturaleza, como la que origina el amor propio, la inclinación entre los sexos, el amor a la descendencia, la gratitud o el resentimiento, pues cualquier instinto de esta clase se ha encontrado en todas las naciones y épocas de forma universal y tiene siempre un objeto preciso y determinado que persigue inflexiblemente" (NHR 40-1).

${ }^{27}$ El hombre sabio no se deja engañar con facilidad, en cambio, el crédulo posee un comportamiento que propicia la irracionalidad y puede desembocar en disposiciones peligrosas como el fanatismo religioso.

${ }^{28}$ El pasaje seleccionado se contextualiza en la sección acerca de los milagros. 
De lo anterior se desprende que, de acuerdo con Hume, un razonamiento 'justo' es aquel que se desarrolla en el dominio causal a través de las ocho reglas ${ }^{29}$, es decir, creencias que son efectivamente conocimiento, que enumera en el THN, de manera tal que busca circunscribir la causación ${ }^{30}$ como un razonamiento confiable de otro que sea injustificado y no creer indiscriminadamente sin una ulterior reflexión ${ }^{31}$. En otras palabras, existe una forma de ser un sabio en medio de la incertidumbre de la probabilidad, pero la fe no es una manera razonable de proceder, ya que el hombre de fe no disciplina la credulidad que experimenta y desatiende la evidencia empírica.

Es significativo considerar que Hume confiere un valor al conocimiento epistémico, pues este no posee suposiciones injustificadas, en consecuencia, prescinde del valor que podrían tener otro tipo de convicciones como la fe.

\section{La fe o superstición en Hume}

La creencia es una disposición que de no ser controlada puede desembocar en credulidad - como es el caso de la superstición. Para aclarar este punto es conveniente tomar en cuenta lo que el autor propone en THN, pues, a reglón seguido, pone como ejemplo una práctica supersticiosa:

Las ceremonias de la religión católica romana pueden tenerse por experimentos de la misma naturaleza. Los devotos de esta extraña superstición se excusan habitualmente de las mascaradas que se les echa en cara, alegando que esos movimientos, posturas y acciones externas avivan su devoción y acrecientan su fervor, que decaería si se dirigiera por completo a objetos distantes e inmateriales. Nos representamos los objetos de nuestra fe, dicen, mediante símbolos e imágenes sensibles, y en virtud de la presencia directa de estos símbolos nos los hacemos más presentes de lo que podríamos hacerlo meramente por una consideración y contemplación intelectuales. Los objetos sensibles tienen siempre más influencia en la fantasía que cualquier otra cosa, y llevan prontamente esta influencia a las ideas con ellos relacionadas y que les asemejan (THN SB 100; énfasis propio).

${ }^{29}$ Cf. nota 26.

30 Por otro lado, la causalidad, para efectos de este artículo, no será profundizada. Esta constituye un tema por sí mismo y no está vinculado necesariamente a la fe, sino que solo nombrada para diferenciar un tipo de creencia que posee fundamento, según el autor, a diferencia de un tipo de credulidad que se convierte en superstición.

${ }^{31}$ Es conveniente recoger el pasaje en que el autor se refiere a la credulidad: "No hay debilidad de la naturaleza humana más universal y patente que lo que comúnmente llamamos CREDULIDAD, o confianza excesivamente ingenua en el testimonio de los demás; y esta debilidad se explica también, y de modo muy natural, por la influencia de la semejanza. Cuando admiramos cualquier cuestión de hecho sobre la base del testimonio humano, surge nuestra confianza exactamente del mismo origen que nuestras inferencias de causas a efectos y de efectos a causas. Y no existe otra cosa que pueda darnos seguridad alguna en la veracidad de los hombres que no sea nuestra experiencia de los principios rectores de la naturaleza humana" (THN 113); es decir, en una inclinación natural. 
La cita seleccionada es esclarecedora: la fe (católica) es una manifestación que se relaciona con la imaginación y no se desarrolla por una especulación intelectual. La fe se constituye como una mera búsqueda de semejanzas ${ }^{32}$ que busca acrecentarla a través de la imaginación, lo cual aparece como una práctica inexplicable. Dado lo anterior, la propuesta humeana subyace parcialmente a la perspectiva del ilustrado ${ }^{33}$, pues, es patente observar que la práctica religiosa es una actividad incomprensible que requiere de imágenes sensibles para acrecentar la imaginación y cumplir con sus ceremonias (como es el caso de la representación de una imagen sensible: por ejemplo, la representación de un hombre crucificado o un Dios padre).

\section{El origen de la fe en la humanidad según Hume}

Los sentimientos religiosos, sostiene Hume, no tienen su fundamento en la razón, sino que, estos se basan en las variadas situaciones a las que la vida de cada persona - dado sus estados contradictorios y cambiantes - es sometida; por consiguiente, se produce una gran preocupación en cada persona cuya motivación es tener alguna injerencia en sus imprevisibles vidas, porque no logran tener control sobre ella. Hume lo expresa de la siguiente manera: "Cada acontecimiento natural se supone gobernado por un agente inteligente. Y no puede acontecer nada favorable o adverso en la vida que no pueda ser objeto de súplicas o acciones de gracias determinadas" (NHR 51). A continuación, el filósofo escocés arguye que la 'curiosidad intelectual' o 'el amor desinteresado por la verdad' no fueron una motivación para dar curso a una investigación sobre la divinidad, sino que su incierta vida es la que moviliza al animal bárbaro, el cual es incapaz de preocuparse por otra cosa que no sea la comida, la venganza, la preocupación por la felicidad o el miedo al futuro, etc. Por ende, la imaginación en cada persona contribuye a conformar diversas ideas sobre los poderes de los que se depende. Ahora bien, con el avanzar del politeísmo se desembocó en el monoteísmo, dado que los sentimientos religiosos transitan entre la adulación y el terror, lo que desembocó, a su vez, en una desmesura en las perfecciones de las deidades que progresivamente dejan de ser varias para convertirse en solo una (inalcanzablemente perfecta).

Es posible observar que Hume, en algunas ocasiones, sostiene que el animal bárbaro de la antigüedad es el mismo sujeto del vulgo ${ }^{34}$ de su tiempo, cuya

\footnotetext{
32 Semejanza entendida como el principio de asociación en la imaginación humeano.

${ }_{33}$ Dentro de la descripción que otorga Hegel.

${ }^{34}$ Los pasajes citados más adelante respecto al vulgo serán exclusivamente en los que Hume refiere a ellos de manera explícita y no al hombre primitivo.
} 
constitución es casi toda la humanidad - lo cual contribuye a establecer un vínculo entre el origen de la religión en NHR y el apartado "Ilustración" de PdG. En NHR afirma: "Por eso todo lugar se halla provisto de una multitud de deidades locales y por eso el politeísmo ha prevalecido y prevalece aún entre la mayor parte de la humanidad inculta (uninstructed mankind)" (NHR 57; énfasis propio) y más adelante "Incluso en la actualidad y en Europa, preguntad a cualquier persona corriente por qué cree en la existencia de un creador omnipotente del mundo. Nunca mencionará la belleza de las causas finales, de las que se halla por completo ignorante [...] Pero os hablará de la muerte repentina e inesperada de alguien, de la caída y contusión de tal otro; de la sequía excesiva de una estación del año; del frío y de la lluvia de otra. Todo esto lo atribuye a la acción inmediata de la providencia" (NHR 79; énfasis propio). Así, es claro que el miedo a los constantes cambios en la vida de los seres humanos conforma una tendencia hacia los sentimientos religiosos; Hume expresa irónicamente que los hombres incultos incurren en una mala comprensión ${ }^{35}$ de los sentimientos religiosos.

\section{La constitución del 'reino del error' en la obra humeana ${ }^{36}$}

La postura ilustrada concibe la estructura del 'reino del error' en una composición que contiene tres partes: el déspota, los sacerdotes engañadores y el vulgo engañado. El déspota y los sacerdotes engañadores poseen 'mala intención', por lo tanto, el ilustrado no dialoga con ellos. En cambio, se dirige al vulgo, para que pueda liberarse del engaño, ya que en ellos existe el germen de la racionalidad, solo que aún no está desarrollada (en términos hegelianos podría entenderse que contienen el germen de la racionalidad en la sustancia).

En el ensayo De la superstición y el entusiasmo Hume manifiesta su perspectiva respecto de los sacerdotes:

Mi primera reflexión es que la superstición es favorable al poder sacerdotal, y el entusiasmo no menos contrario a él que la sana razón y la filosofía, o incluso más contrario que éstas. Una superstición se basa en el miedo, la tristeza y una depresión del ánimo. Representa a la persona ante sí misma de manera tan despreciable que aparece ante sus propios ojos indigna de acercarse a la presencia divina, y es natural que recurra a otra persona cuya santidad de vida, o cuyo descaro y astucia, han hecho que se la suponga más favorecida por la Divinidad. A esta persona le confían los supersticiosos sus devociones. A su cuidado encomiendan sus plegarias, peticiones y sacrificios, y por este medio esperan hacer que sus ruegos resulten aceptables para la Deidad encolerizada. Tal es el origen de los sacerdotes, a los que con razón cabe considerar invención de una superstición timorata y abyecta que, en su perenne desconfianza, no

\footnotetext{
35 El filósofo escocés hace alusiones a dos tipos de falsas religiones y una verdadera; la verdadera tiene solo un cariz intelectual, por el que se accede a través de la filosofía, pero no se lleva a cabo mediante una religiosidad colectiva.

${ }^{36}$ La obra humeana se refiere a las obras que se menciona en la bibliografía.
} 
se atreve a ofrecer su propia devoción y piensa, en su ignorancia, propiciar a la Deidad gracias a la mediación de sus supuestos amigos y servidores (Hume 2011 99; énfasis propio).

En la lectura que se ha seguido es evidente que hay engañados, los supersticiosos, y los engañadores, sujetos que hacen mal uso de su razón para engañar a aquellos ignorantes que temen por su bienestar dadas las circunstancias imprevisibles en la que se encuentra la vida humana. En NHR también existen afirmaciones similares de lo señalado en el pasaje recién citado:

La historia real ${ }^{37}$ de sus aventuras, trastocada por la tradición y ensalzada fantasiosamente, se convirtió en una fuente inagotable de fábulas, especialmente al pasar por las manos de los poetas, autores de alegorías, y sacerdotes, quienes de forma sucesiva acrecentaron la admiración y el asombro de la muchedumbre ignorante (NHR 75).

Por otro lado, queda observar qué sucede con el vulgo engañado, si es que efectivamente cumple las características para representarlo como una masa con racionalidad rudimentaria, al menos en las citas mencionadas ellos sí son engañados. Es conveniente volver al autor: "La razón, cuando es obvia, impide esas corrupciones ${ }^{38}$; cuando es abstrusa, mantiene esos principios completamente fuera del alcance del vulgo, que es el único inclinado a corromper cualquier principio u opinión" (NHR 47; énfasis propio). En otras palabras, la razón, al no estar desarrollada, es fácil de ser manipulada (como en el caso de la masa que tiende a tergiversar la recta razón). Por ejemplo, leemos en el siguiente pasaje:

Pues los hombres que, debido a prejuicios supersticiosos, han aprendido a poner énfasis en el sitio equivocado, cuando esto les falla y descubren reflexionando un poco, que el curso de la naturaleza es regular y uniforme, toda su fe se tambalea y sucumbe. Pero cuando una mayor reflexión les enseña que precisamente esa regularidad y uniformidad son las pruebas más sólidas de un designio ${ }^{39}$ y de una inteligencia suprema, retornan a esa creencia que habían abandonado y son ahora capaces de basarla en una fundamentación más firme y duradera (NHR 81; énfasis propio).

En la cita expuesta se busca señalar cómo Hume sostiene que, si los hombres reflexionan con detenimiento, estos podrán abandonar la superstición que les fue enseñada (en ellos existe racionalidad). Por consiguiente, existen los suficientes indicios para sostener que es un autor parcialmente ilustrado, pues, el filósofo escocés busca comunicarse con el vulgo, ya que (como se ha visto) son la mayor

\footnotetext{
${ }^{37}$ De los héroes que se convirtieron en deidades.

38 Argumentos de la razón que devienen en opiniones y caen en el olvido, Hume parece tener la consideración platónica clásica entre $\delta o ́ \xi \alpha$ y $\dot{\tau} \tau \iota \sigma \tau \eta \dot{\mu \eta}$, lo cual se condice con la separación que hace el autor entre conocimiento amparado en la experiencia y mera especulación.

${ }^{39}$ Hume afirma al comienzo de NHR que es posible que exista un Dios creador basándose en el orden de la naturaleza, a saber, el conocido 'argumento del diseño' que también es analizado en Diálogos sobre la religión natural.
} 
parte de la humanidad, las cuales (si se lo propusieran) podrían liberarse del engaño que han sufrido por culpa de la credulidad que existe en ellos, dicho de otro modo, podrían convertirse en sabios si restringieran su creencia a la evidencia.

En esta última dirección, parece razonable considerar que la propuesta humeana se identifica en parte con el 'reino del error', puesto que existe la 'mala intención' que manipula los afectos de la 'mala intelección' o el vulgo ignorante. Si a lo anterior se le agrega el llamado a la sabiduría que el autor realiza, se vuelve manifiesto que Hume busca que los lectores se liberen de la mala comprensión y la manipulación de los sacerdotes 'astutos' y 'descarados'.

\section{La mala comprensión de la fe en la obra humeana}

En la obra de Hume muestra aspectos que permitirían afirmar que éste mal entendería el objeto de la fe. Lo anterior, resulta en una comprensión empobrecida de la misma, pues, relega una arista importante: la confianza que existe en cada integrante de la comunidad religiosa y el reconocimiento que tiene cada uno de ellos en su congregación.

En puntos previos, se buscó poner en evidencia que el filósofo escocés exhorta al lector a no convertirse en un crédulo que pueda admitir cualquier tipo de superstición, sino más bien, lo invita a transformarse en un 'hombre sabio' y para lograrlo debe circunscribirse a la experiencia. Además, en NHR, repara en los ritos de la eucaristía (a saber, en la comunión) dado que para Hume es inconcebible que Dios se encuentre en un trozo de pan:

Creo que no existe ninguna afirmación en todo el paganismo que ofrezca una posibilidad tan adecuada para hacer el ridículo como la que afirma la presencia real [de Cristo en la Eucaristía]: es tan absurdo que escapa a la fuerza de todo argumento. [...] pidieron a Mustafá con mucha insistencia que se convirtiese al cristianismo y le prometieron, para animarle, vino bueno y abundancia en este mundo y paraíso en el otro. Estos alicientes fueron demasiado poderosos para resistirse. Y por ello, después de haber sido bien instruido y catequizado, estuvo finalmente de acuerdo en recibir los sacramentos del Bautismo y de la Cena del Señor. El sacerdote, sin embargo, para asegurar y consolidar todo bien, continuó todavía su enseñanza y empezó al día siguiente con la pregunta habitual: ¿Cuántos dioses hay? Ninguno, contestó Benito, pues ése era su nuevo nombre. ¡Cómo! ¡Ninguno!, gritó el sacerdote. Segurísimo, dijo el honrado prosélito. Siempre me ha dicho que no existe más que un solo Dios, y ayer me lo comí (NHR 109; énfasis propio).

Posteriormente, prosigue con su crítica a los ritos católicos, los cuales censuran a los paganos, pero no reparan en que realizan los mismos actos incongruentes que rechazan en otras prácticas religiosas:

¿Cómo podéis venerar puerros y cebollas?, podemos suponer que dice un doctor de la Soborna a un sacerdote de Sais. Si los veneramos, respondería este último, al menos no nos lo comemos también. Pero ¿Qué extraños 
objetos de adoración son los gatos y monos?, diría el ilustrado doctor. Son al menos tan buenos como las reliquias o huesos putrefactos de los mártires, contestaría su no menos ilustrado antagonista. ¿No está usted loco, insiste el católico, cuando degüella a otro por preferir un repollo o un pepino? Sí, dice el pagano, lo admito, si usted confiesa que aún están más locos quienes pelean por preferir unos tomos de sofisterías a otros, diez mil de los cuales no valen siquiera lo que un repollo o un pepino (NHR 111; énfasis propio).

Los últimos dos pasajes citados aluden a las ceremonias de la religión católica indicada anteriormente, donde tales prácticas se tornan incomprensibles para el filósofo escocés, debido a que exaltan a la imaginación a través de objetos materiales como: un trozo de pan y el vino los cuales se 'transforman' en el cuerpo y sangre de Cristo.

Hume sostiene, por una parte, que el Dios católico es un mero objeto, por otra parte, sostiene que a través de la verdadera filosofía se llegará a la auténtica religión, revelando que Dios es el diseñador de la naturaleza. Pero, tal perspectiva solo toma en cuenta un aspecto de la fe, es decir, es un análisis incompleto. Siep expresa el comportamiento equívoco del ilustrado de la siguiente manera: " $\mathrm{La}$ Ilustración es igual a la consciencia del sacerdote o de los teólogos en la medida en que ella misma mal interpreta la fe en la forma cosificada que crítica la "superstición»" (197; énfasis propio). Por lo tanto, Hume se suscribe, en cierta medida, a la postura ilustrada, puesto que ha malinterpretado a la fe: la ha concebido de modo cósico u objetual, entendiendo a Dios meramente como el pan, el vino en la eucaristía y las reliquias, lo cual ha calificado como una conducta ridícula.

\section{A modo de conclusión}

Se considera importante tomar en cuenta que la postura humeana respecto a un Dios creador no es algo que el filósofo escocés desestime, pues, es patente que en el comienzo de NHR el autor considera aceptable la posibilidad de que exista un Dios diseñador; por lo tanto, la crítica a algunos ritos religiosos no constituye una mera apología de ateísmo, más bien busca inhabilitar nociones como la concepción de un Dios unitario que supuestamente serían algo inherente a la mente de los seres humanos.

Por otro lado, el conocimiento de la 'naturaleza humana' o 'ciencia del hombre', tal como la concibe Hume, se ve limitada si solo se considera a la experiencia como la regla que otorga seguridad al saber. No todo conocimiento humano se puede reconocer mediante el estudio detenido de objetos físicos: por ejemplo, conceptos como la libertad, la justicia o la confianza, siguen constituyendo un objeto de estudio filosófico y no se pueden comprender a cabalidad solamente a través de un estudio especulativo. 
Finalmente, la perspectiva con la que Hume concibe la práctica religiosa tiene como consecuencia que solo logra comprender a la fe de modo cósico, es decir, la considera como adoración a entes físicos y deja de lado elementos como la confianza en la que cada sujeto se reconoce a sí mismo y a otros miembros de su comunidad $^{40}$. A partir de lo anterior, mediante el análisis de ciertos párrafos de $P d G$ - en paralelo con literatura humeana - se comprobó que la perspectiva del filósofo escocés de la fe es parcialmente ilustrada. Esto último, da como resultado que existen limitaciones en el análisis humeano respecto de su objeto de estudio: no es posible reducir todo conocimiento al método experimental anclado en la experiencia, pues, reduce considerablemente otro tipo de estudios que no son abordables para las ciencias empíricas.

\section{Bibliografía}

Bailey, Alan and O'Brien Dan. The continuum companion to Hume. London: Continuum, 2012.

BeeBee, Helen. Hume on causation. Oxford: Oxford University Press, 2006.

Hegel, G. W. F. (PdG) Fenomenología del Espíritu, trad. W. Roces, México D.F: Fondo de Cultura Económica, 1966.

Hume, David. (THN) Tratado de la naturaleza humana, trad. Félix Duque, Madrid: Tecnos, 1988.

Hume, David. (EHU) Investigación sobre el entendimiento humano, trad. Vicente Sanfélix Vidarte y Carmen Ors Marqués, Madrid: Istmo, 2004.

Hume, David. (NHR) Historia natural de la religión, trad. Concha Cogolludo, Madrid: Trota, Edición bilingüe, 2003.

Hume, David. Ensayos morales, políticos y literarios, trad. Carlos Martín Ramirez, Madrid: Trotta, 2011.

Siep, Ludwig. El camino de la fenomenología del espíritu, trad. Carlos Emel Rendón, Barcelona: Anthropos Editorial, 2015.

\footnotetext{
${ }^{40}$ El ilustrado busca que el vulgo sea autoconsciente, pero en la liturgia cada individuo se vuelve autoconsciente con otros. Así, fracasa el objetivo de la ilustración, pues los creyentes no se vuelven autoconscientes al darse cuenta de que los objetos son entidades materiales (esto no lo han olvidado).
} 